\title{
EAP UTILIZATION PATTERNS AND EMPLOYEE ABSENTEEISM: RESULTS OF AN EMPIRICAL, 3-YEAR LONGITUDINAL STUDY IN A NATIONAL CANADIAN RETAIL CORPORATION
}

\author{
Ashley Spetch, Alex Howland, and Rodney L. Lowman \\ Alliant International University
}

\begin{abstract}
Despite the increasing need for employee assistance program (EAP) providers and human resources (HR) departments to demonstrate outcomes resulting from the availability and use of EAP services, few empirical studies have examined the relationship between EAP utilization and objective organizational outcome measures. This study made use of a unique longitudinal archival data set to examine EAP utilization, the problems for which help was sought, and the relationship of EAP utilization to absenteeism over 3 consecutive years among all EAP-eligible $(N=3,448)$ employees in all locations of a large national Canadian retail store. Patterns of usage were examined by gender and age with a clearly defined EAP utilization statistic. Most frequently, the reasons for help seeking were personal issues, marital/family problems, and (a distant third) work-related issues. Longitudinal hierarchical linear modeling (HLM) was used to examine the differences in yearly absentee hours between EAP users versus non-EAP users. The results showed that EAP users generally had higher rates of absenteeism than nonusers during the year in which EAP was used but (with some exceptions) did not differ from the non-EAP user groups in the year(s) before and after treatment. Implications for consulting psychology are suggested.
\end{abstract}

Keywords: employee assistance programs, EAP utilization, absenteeism

Consulting psychologists often emerge from clinical and counseling psychology backgrounds. As they gravitate to organizational consulting roles, they are naturally well suited to become

Editor's Note. Robert Kaiser served as Action Editor for this article.-RLL

Ashley Spetch, Alex Howland, and Rodney L. Lowman, Organizational Psychology Division, California School of Professional Psychology (CSPP), Alliant International University.

This research was initially completed as part of a 2nd Year Consulting Psychology PhD Program Research Project by the first two authors under the supervision of the third author.

The authors acknowledge the contribution of Homewood Human Solutions and the Canadian national corporation for providing access to the data reported in this study.

Correspondence concerning this article should be addressed to Ashley Spetch, Organizational Psychology Programs/CSPP, Alliant International University, 10455 Pomerardo Road, San Diego, CA 92131. E-mail: aspetch@alliant.edu; ahowland@alliant.edu; rlowman@alliant.edu 
involved with occupational mental health counseling programs (see, e.g., Lowman, 1993, 2002). These programs typically combine individual and organizational levels of consultation. As consulting psychologists, employee assistance programs (EAP) managers and providers need to be concerned with the organizational level outcomes of such programs.

EAPs are in widespread use by employers. The majority of large employers offer EAPs not only to increase the individuals' well-being but also to increase productivity and performance among employees (Cooper, Dewe, \& O'Driscoll, 2003; Csiernik, 2002; Murphy, 2000; Selvik, Stephenson, Plaza, \& Sugden, 2004). As of 2002, 90\% of Fortune 500 firms offered EAP services (Merrick, Volpe-Vartanian, Horgan, \& McCann, 2007). Although early EAPs were originally developed to serve employees who suffered from alcohol and drug abuse, today most EAPs provide services to employees experiencing an assortment of personal problems; that is, they are "broad-brush" versus single-purpose EAPs. Typical problems addressed by EAP services include depression, stress, relationship, marital, gambling, career, financial and legal, child and elder care, health and wellness, and violence issues (Johnson, 2008), but increasingly EAP staff may address workplace issues such as conflict and interpersonal difficulties.

Despite the sustained popularity of EAPs and services, EAP providers and human resource departments are receiving increased pressure to demonstrate positive outcomes resulting from EAP services. EAP providers argue that implementation of EAP programs can help reduce absenteeism, turnover, disability, and presenteeism ${ }^{1}$ while also increasing morale and productivity. Despite these claims, few empirically sound studies have linked EAP services to objectively measured organizational outcomes such as absenteeism, productivity, or even job satisfaction and motivation.

In this study, we focus on absenteeism as an outcome variable associated with EAP use. Previous research (e.g., Hays, Wells, Sherbourne, Rogers, \& Spitzer, 1995; Ulleberg \& Rundmo, 1997) has linked employee absenteeism to psychological distress. EAPs are intended to reduce psychological distress and therefore could be expected to improve workplace outcomes (Attridge et al., 2009). The few empirical studies directly examining EAP utilization and organizational outcomes such as absenteeism have reported mixed results, and most of these studies have suffered from significant limitations (Arthur, 2000; Courtois et al., 2004). The purpose of the present study is therefore to extend the literature by examining EAP utilization and its relationship with absenteeism in an unusual national multiyear sample. Additionally, this study provides an interesting profile of EAP users, and the problems for which they sought help, in a unique longitudinal sample.

Specifically, this study aims to do the following:

1. Identify yearly EAP utilization rates among all EAP-eligible employees of a Canadian national retailer, the demographic characteristics of users, and the reasons for utilizing EAP, across a 3-year period.

2. Compare yearly absenteeism differences of EAP users versus non-EAP users within and across years using longitudinal hierarchical linear modeling (HLM).

\section{Literature Review}

\section{EAP Utilization Rates and Measurement Issues}

EAPs are usually available to all organizational employees (and often to their family members as well). A fair amount of research has addressed the question of utilization of the services by eligible employees and, if relevant, their dependents. The EAP utilization literature has explored the percentage of employees participating in EAP services (Courtois et al., 2004; Csiernik, 2003; Employee Assistance Professionals Association [EAPA], 2009; Mulligan, 2007); the demographics of users (Blum \& Roman, 1992; French, Dunlap, Roman, \& Steele, 1997; Panks, 2001; Poverny \&

\footnotetext{
${ }^{1}$ Presenteeism is defined as being physically present at work but with reduced productivity because of illness or events that distract employees from their tasks (Hummer, Sherman, \& Quinn, 2002; Johns, 2010; Whitehouse, 2005).
} 
Dodd, 2000; Selvik et al., 2004); voluntary versus referral utilization (e.g., Blum \& Roman, 1992; Greenwood, DeWeese, \& Inscoe, 2005); differences of EAP offerings (e.g., Weiss, 2003); and program promotion (e.g., Azzone et al., 2009; Csiernik, 2002; Mazloff, 1996; Mulligan, 2007) on EAP utilization. Other researchers have examined the underlying problems that drive individuals to utilize EAP services (e.g., Macdonald, Wells, Lothian, \& Shain, 2000; Mulligan, 2007; Poverny \& Dodd, 2000; Selvik et al., 2004; Shumway, Wampler, \& Arredondo, 2004). In the present study, we first examined the percentage of employees who utilized EAP clinical counseling services, user demographics, and the problems that lead individuals to seek EAP services in and across 3 years.

EAP utilization measurement issues. Organizations and EAP providers often use EAP utilization rates as an outcome measure of the success of the EAP. Although, by itself, this is at best an ambiguous outcome measure, increased rates of utilization are typically considered to be a sign of EAP success. Both EAP providers and sponsoring organizations typically compare their utilization rates with industry and national benchmarks (EAPA, 2009). Making comparisons across organizations has been challenging because of the various ways in which EAP utilization has been calculated (Attridge et al., 2009; Courtois et al., 2004; Csiernik, 2003; EAPA, 2009; Jacobson \& Jones, 2010; Mulligan, 2007). However, there is considerable variability in the literature about how best to measure EAP utilization.

EAPA (2009) has stated that the typical definition of EAP utilization is the number of new EAP cases opened within a given time period (typically a year) divided by the total number of employees eligible for EAP services. Although this formula appears fairly straightforward, in its practical application there remains considerable ambiguity even in that definition. For example, what constitutes a case? When employees' dependents use EAP services, should that usage be included as a case? What happens when the same employee seeks EAP services multiple times for different purposes over the course of the same year? Does an EAP-using employee who is provided training sessions (e.g., on employee well-being) constitute a case? Ambiguities in the definition have resulted in a considerable variation on reported utilization rates, making it difficult to compare programs and set benchmarks (EAPA, 2009). Additionally, there may be incentives for EAP providers to make their utilization rates seem high to justify the existence or expansion of the program.

Attridge et al. (2009) identified three different types of utilization statistics typically calculated to measure EAP utilization. The first metric, the clinical case use rate, consisted of the number of employees and family members who have received a clinical assessment, and who had at least one counseling session in a given time period, divided by the total number of EAP-eligible employees (dependents are not included in the denominator). Attridge et al. reported that the clinical case use rate using that definition typically ranges from $1 \%$ to $5 \%$ or higher annually. Their second metric counts the total number of people accessing EAP services for any reason (clinical counseling, information and referral, management or organizational services, workshops, crisis management, etc.) divided by the total number of EAP-eligible employees (again, no dependents are included in the denominator). Attridge et al. (2009) suggested that this measure, termed the people use rate, usually falls in the $5 \%$ to $15 \%$ rate. The third utilization metric is called the total activity use rate and includes services included in the first and second rate measures, as well as all EAP calls, Web site hits, and sessions of clinical counseling. Use under all of these categories are added up and divided by the total number of eligible employees (again, without dependents). Attridge et al. suggested that the total annual activity use rate typically falls between 15 and $30 \%$.

Csiernik (2003) collected EAP utilization surveys from 102 Canadian companies and found the average annual reported utilization rate to be $9.2 \%$, with a range of $1 \%$ to $30 \%$. However, not atypically in the literature, Csiernik provided no single operational definition for utilization. Indeed, of the 102 utilization rates reported in this study, there were 19 different methods used to calculate the reported figures. The most prominent formula used (39/102 reports) was new "files" divided by the number of employees (presumably within a given year). What constituted a new file was also inconsistently defined (e.g., sometimes employees' dependents constituted new files; other times they did not). Of the companies in this study, 14 reported calculating utilization rates by number of employees (no dependents) divided by number of employees. In another study sampling Long Island, a majority (111/129) of New York companies reported an 8\%-10\% EAP utilization rate 
(Mulligan, 2007). The utilization rates were collected through self-report from individual organizations, and data on how utilization was calculated were not collected in this study.

There is thus considerable variability in the literature on the seemingly simple question of EAP utilization rates. In an effort to combat the ambiguities in determining utilization rates, a few remedies have been proposed (Attridge et al., 2009; Csiernik, 2003; EAPA, 2009). Although a detailed description of these three techniques is beyond the scope of this article, two key implications are suggested from these approaches. First, consulting psychologists involved with EAPs need to be clear on what definition of utilization they are using to report (or to evaluate) EAP utilization. The approach used should be determined a priori and should be kept constant over time so that cross-year comparisons are meaningful. Second, when reporting EAP utilization rates, especially in research contexts, it is important to provide precise details in how utilization rates were calculated and not to mix and match rates on the basis of different calculation formulae.

In the present study, we used what we regard as the most important utilization rate in considering the impact of EAP use on employer-relevant outcomes: the yearly number of all eligible employees who utilized EAP counseling divided by the total number of eligible employees. Not only can this metric be reliably measured, but employees' use of EAP counseling services likely has the most direct effect on organizational outcomes, the focus of our research. Ambiguities and deviations in how many dependents are EAP eligible act as confounds when trying to compare utilization rates across companies. Also, including dependents' use of EAP services in the numerator while calculating utilization artificially inflates utilization rates and may mislead as, arguably, dependents' use likely has fewer effects on organizational outcomes. Because there was not a basis for hypothesizing anything specific about the findings in our unusual longitudinal data set, no hypothesis was made about the level or amount of EAP utilization across the 3 years of the study.

Demographics of EAP users. Beyond overall measures, there has been considerable research conducted on the demographics of those utilizing EAP services (e.g., Blum \& Roman, 1992; French et al., 1997; Gerstein, Moor, Duffey, \& Dainas, 1993; Panks, 2001; Poverny \& Dodd, 2000). Demographic variables examined in these studies typically have included gender, age, organizational tenure, education, marital status, race, ethnicity, and occupation. For the purposes of this study, we focus on utilization rates by gender and age, as these comparisons are the most highly represented in the existing EAP utilization literature.

In comparing EAP use across gender, there have been inconsistencies in the literature and across samples. Women have often been found to be underrepresented in EAP caseloads in which the research focused on EAPs that served predominately alcohol-related problems (Cahill, Volicer, \& Neuberger, 1982; Gerstein et al., 1993; Young, Reichman, \& Levy, 1987). With some exceptions (e.g., Milne, Blum, \& Roman, 1994), however, women are typically overrepresented in broad-brush EAP caseloads (Blum, Martin, \& Roman, 1992; Blum \& Roman, 1992; French et al., 1997; Harris \& Fennell, 1988; Poverny \& Dodd, 2000). Because the EAP services provided to the organization under investigation are consistent with broad-brush services, we hypothesized the following:

Hypothesis 1: Women will have higher EAP utilization rates than men across the 3 years of this study.

We were surprised to find only one empirical study that considered age as a predictor of the likelihood of EAP usage (French et al., 1997). French et al. examined EAP usage at six worksites across the United States and found age to be a significant predictor of EAP usage at only one of the six worksites. At that one site, the likelihood of using the EAP decreased with age. Because five of six worksites showed no association between age and likelihood of using EAP services, we hypothesized the following:

Hypothesis 2: EAP utilization rates will not vary by age across the 3 years of the study.

Reasons for seeking EAP services. Current research has demonstrated that the majority of EAP cases are self-referred employees suffering from psychological/emotional problems, family problems, and work-related problems (Macdonald et al., 2000; Mulligan, 2007; Murphy, 2000; 
Poverny \& Dodd, 2000; Shumway et al., 2003). Although these problems typically constitute the top three reasons for utilizing EAP counseling, the order of utilization varies across samples and studies. Other problems leading to EAP use include medical, legal, and alcohol/substance abuse problems (Shumway et al., 2003). It would be expected that those with untreated problems of this type would be at high risk for absenteeism and other problematic workplace behaviors.

A gender difference in the reason for EAP use has also been reported. Poverny and Dodd (2000) examined EAP use of a sample of 267 staff and faculty members at a university in 1996. The researchers found women were more likely to use the EAP for job-related and personal/ psychological problems than men but that men were more likely to use the EAP for alcohol reasons.

We predicted the following in our study:

Hypothesis 3: The "big three" problems (psychological/emotional, marital/family, and workrelated problems) will be the top three reasons for seeking help across all 3 years of the study, and men and women will differ in the order of their top three reasons for help-seeking problems.

\section{EAP and Organizational Outcomes}

EAP providers, who may have a vested interest in such claims, often tout the positive outcomes on organizational variables of EAPs, but there is surprisingly little empirical research in support of such claims. From the standpoint of adverse effects, research has established that emotional and personal problems have been associated with increases in absenteeism, tardiness, sick leave use, injuries on the job, and medical claims (Carr \& Hellan, 1980). Many employers and EAP providers (e.g., Every \& Leong, 1994; Greenwood et al., 2005; Hargrave, Hiatt, Alexander, \& Shaffer, 2008; Petersen, 1972; Selvik et al., 2004) claim that EAP services are effective in reducing employees' emotional and personal problems and therefore assume that EAPs indirectly reduce absenteeism and disability. Despite these claims, however, few empirically sound studies have examined whether EAPs in fact have a positive impact on organizational-level outcome measures (Arthur, 2000; Courtois et al., 2004). The studies that do report organizational outcomes (e.g., Alander \& Campbell, 1975; Asma, Hilker, Shevlin, \& Golden, 1980; Freedberg \& Johnston, 1979; Foote, Erfurt, Strauch, \& Guzzardo, 1978; Groeneveld \& Shain, 1985; Petersen, 1972) were typically focused on EAP services that primarily dealt exclusively with alcohol problems and cases in which supervisors were required to refer employees who, they suspected, abused alcohol to the company's EAP (Macdonald et al., 2000). Because most EAPs today are broad brush, the earlier research cannot be assumed to generalize (Arthur, 2000; Macdonald et al., 2000).

More recent empirical research with a broader range of problems has not supported the same relationship between EAP utilization and positive organization outcomes. For example, Macdonald, Lothian, and Wells (1997) used a matched case-control study design and found a significant increase in employee absenteeism after EAP use. This study examined employee absenteeism records at three time points: 60 days counted back from the first day of treatment, 60 days from the first day of treatment, and then 60 days after the 61 st day after the first treatment. They found that those who received EAP services had higher absenteeism rates both pre- and posttreatment, compared with a matched control group. Because of statistical limitations, they were unable to accurately examine differences between EAP users and their matched controls during the EAP treatment period. Macdonald et al. (2000) replicated this same study design with a different employer that used a different, external EAP provider. The results were the same as for the first study, providing further evidence to suggest that utilization of EAPs may actually result in increased absenteeism among those seeking help. A major caveat of these two studies, however, is how the researchers developed matched control groups. Although the matched control groups were matched on age, gender, occupational status, and length of employment, there was no control match for the issues that influenced the use of EAP services (e.g., matching with employees who also had marital and family issues, stress, or alcohol abuse). Another limitation of these studies was that absentee rates were only observed for 60 days before, during, and after treatment. Employees typically utilize EAP counseling once they have incurred a problem, and the problems for which help was sought 
are often complex and unlikely to be resolved within that time frame. In the present study, we address this gap in the literature by comparing users of EAP services to all non-EAP users within and across the 3-year period of the study.

Although the reviewed studies did not show positive organizational outcomes from EAP, other more recent studies have demonstrated positive organizational impact as a result of EAP services (e.g., Hargrave et al., 2008; Hargrave, Hiatt, \& Shaffer, 2007; Mulligan, 2007). Hargrave et al. (2007) had EAP clients self-report absenteeism among other organizational outcome indicators and suggested that employees estimated that they would have missed, on average, an additional 1.86 and 2.60 days of work had they not been helped through the EAP treatment (Hargrave et al., 2008). Although subjective outcomes showed positive findings, a significant limitation of these studies is the risk of self-report and retrospective bias. Numerous authors have called for studies that are less biased and more methodologically sound (Arthur, 2000; Lennox, Sharar, \& Burke, 2009; Pompe \& Sharar, 2008; Tisone, 2008). Clearly, it remains to be established whether these positive organizational absenteeism outcomes will replicate when more objective measures of absenteeism are used. The present study aims to examine differences in rates and trends of yearly absenteeism between EAP users and nonusers employed at the same organization within and across 3 years with objective (rather than self-report) data.

\section{Absenteeism}

Absenteeism has been widely studied in the industrial-organizational (I-O) psychology literature but rarely in the context of personal problems such as those for which EAP care would be sought. Existing I-O literature on absenteeism has tended to focus on the impact of job satisfaction, showing mixed results with typical correlations of around .20 (e.g., Farrell \& Stamm, 1988; Johns, $1997,2001)$. The assumption in such research is that absenteeism is the manifestation of dissatisfaction with one's work. Other studies (e.g., Hays et al., 1995; Ulleberg \& Rundmo, 1997) have examined psychological distress as a predictor of absenteeism. For example, Johns and Xie (1998) found that self-report measures indicated that depression was more frequently cited as a cause of absenteeism than was workplace dissatisfaction. Cohen and Williamson's (1991) stress-illness pathways model suggests that stress leads to weakened immune system functioning and increased propensity for physical illness. Although absenteeism is often thought of as a reaction to illness, it has also been noted as being a way to cope directly with psychological distress (Hackett \& Bycio, 1996), supporting two mechanisms to explain the associations between psychological problems and workplace absenteeism.

In the present study, the EAP used short-term cognitive-behavioral therapy (CBT), a type of psychotherapy that emphasizes how thoughts lead to emotions and subsequent behavioral manifestations (Barlow, 2008). Absenteeism can, in this context, be conceptualized as a behavioral manifestation of psychological dysfunction. In this model, CBT offered through an EAP can help people to more appropriately appraise a situation and regulate emotions (Barlow, 2008), possibly leading to increased capacity to deal with problems without withdrawal behaviors such as absenteeism. Because of psychological problems and possible subsequent physical illness (Cohen \& Williamson, 1991), employees will consequently have higher absenteeism during the time they are in need of psychological assistance. Consistent with the EAPs provide coping strategies and behavioral modification (e.g., Barlow, 2008), we also hypothesized that absenteeism will primarily be associated with acute problems and, accordingly, we expected the absenteeism rate to return to baseline as employees reap the benefits of EAP. This led to the following hypothesis:

Hypothesis 4: Employees who utilized EAP counseling will have higher absenteeism rates in the year in which they access EAP counseling than other employees who did not use EAP in that year, but the groups will not differ in either the year before EAP usage or in the year after EAP usage. 


\section{Method}

\section{Participants}

The initial data set included information for 3,448 EAP-eligible employees who were employed across Canada in 89 separate stores/units/departments of the retail company. The participants consisted of 1,429 male (41.4\%) and 2,019 female (58.6\%) employees. Their ages ranged from 16 to 67 years $(M=38.0, S D=10.0)$. When calculating yearly utilization rates, we initially considered only those eligible for EAP within a particular year. Thus, in Year 1, there were 3,080 EAP-eligible employees; in Year 2, 3,239 eligible employees, and in Year 3, 3,135 eligible employees. To be included in the final analysis that examined the relationship between EAP utilization and absenteeism, employees were required to have been employed with the organization for all 3 years, resulting in a final sample size of 2,584 employees. Thus, the sample used for this study comprised $80 \%$ of the entire sample of employees eligible 1 or more years of the 3 -year study. Those who were not eligible for EAP services for all 3 years were dropped for two reasons. First, it was impossible to know in this data set when employees who had only been with the company for a partial year left the organization within a given year. Thus, determining accurate absentee rates for the year when the employees left was not possible for part-year employees. Second, the researchers wanted to focus more on absentee rates than turnover rates for the present research. Finally, we note that, although we had planned to consider the results at the store/unit level, we did not do so because of the relatively large amount of movement of employees from one store to another during the 3 years the study examined.

\section{Data Sources}

EAP use and eligibility data were provided by the company's external EAP provider for all individuals employed at a large Canadian retail corporation over a 3-year period. The EAP provider was a large Canadian firm that provides EAP services across Canada. Absenteeism data for the company for the same 3-year period were provided by the employer. These two data sets were combined by the use of unique employee numbers that the EAP provider and the employer used to identify individual employees. (All names had been removed from both sets of data before being sent to the researchers.) Once the data were merged by the researchers, each employee's number was changed to a randomly generated number to ensure complete confidentiality as to employees' identity.

The EAP data from which we worked included five eligibility lists that spanned the same 3-year period as that for the EAP use and absenteeism data. Each eligibility list included all employees who were eligible to utilize EAP services at that time point (dependents were not included in this study). The data from the EAP provider included all employees who had received a minimum of one counseling session during the covered years and also had data on the EAP users' age, gender, reason for seeking counseling, and year of counseling. The employer's absenteeism data set included employee identification numbers, age, gender, and number of absentee hours incurred per annum during the 3-year period.

\section{EAP Annual Utilization Rate Calculation}

Utilization of EAP services was calculated by taking the total number of employees in a given year who used EAP counseling services and dividing that figure by the total number of employees eligible in that particular year (dependents were excluded). For purposes of our research, employees were considered to have used EAP counseling if they attended at least one counseling session in a given year. Regardless of the number of sessions or EAP cases created in a given year, employees were counted only once when calculating utilization rates. (This method of calculating utilization eliminated the overestimation that sometimes occurs in such rates by including dependents, retirees, or employees who seek EAP for multiple issues, as cases in the numerator for this calculation.) EAP eligibility was determined by examining eligibility lists provided by the retail company to the EAP provider. 


\section{Statistical Analyses}

We used HLM to effectively capture the relationship between EAP use and yearly absenteeism across 3 calendar years. This technique takes into account the nesting of data that occurred in this study in having multiple observations over time of the same persons. Thus, in this research, time points, or occasions, were nested within persons (Raudenbush \& Bryk, 2002).

Use of HLM allowed us to examine whether there was significant individual variation around the mean trajectory of absenteeism. HLM also made it possible to consider the effects of predictors (e.g., EAP use) of absenteeism at both the starting point (intercept) and rate of absenteeism change (slope). Finally, the technique allowed for the examination of nonlinear change in absenteeism across years. For example, it was hypothesized that those who used EAP during Year 2 of the study would have lower absenteeism the year before receiving EAP services, increased absenteeism the year EAP services were received, and a return to lower absenteeism the year after EAP services (i.e., a quadratic trend in absenteeism over the course of the study). In our study, change in time (both linear and quadratic change) represent Level 1 predictors. Gender, age, whether employees transferred store location (yes or no), and EAP use within each year (i.e., EAP Year $1=$ yes or no; EAP Year $2=$ yes or no; EAP Year $3=$ yes or no) were used as Level 2 predictors.

Finally, we note that individuals were nested within stores throughout Canada, suggesting the need for a three-level model (i.e., time nested within individuals, nested within stores), but because of the high transfer rates of employees between stores, we chose to proceed with a two-level model and used store transfer (moved or did not) as a control variable in our analyses. ${ }^{2}$

\section{Results}

The number of eligible employees, number of EAP cases, and the percentage of EAP utilization in Years 1, 2, and 3 are presented in Table 1. Yearly EAP utilization rates were the highest in Year 1 $(11.7 \%)$, then decreased in Year $2(8.4 \%)$ and then again in Year $3(8.0 \%)$. The variance in utilization rates across the 3 years was statistically significant, $\chi^{2}(2)=30.92, p<.05$. Across the 3 years, the average yearly utilization rate was $9.4 \%$.

\section{EAP Utilization Across Demographics}

After calculating total utilization rates, we also compared rates by gender and age. Utilization rates by gender can be found in Table 2 . Women had significantly higher utilization rates than men in all 3 years of the study: Year $1, \chi^{2}(2, N=3,180)=30.77, p<.001$; Year 2, $\chi^{2}(2$, $N=3,239)=12.91, p<.001$; Year $3, \chi^{2}(2, N=3,135)=7.09, p<.01$. Across all 3 years of this study, female employees' annual utilization rates averaged $11.1 \%$, whereas male employees' average annual utilization rate was $6.7 \%$. Over the 3 years, an average of $70 \%$ of EAP cases were opened by female employees, although they only represented $58.7 \%$ of the sample. Thus, Hypothesis 1 (that women would use the EAP more than men) was supported.

Utilization across age groups can be found in Table 3. Across 3 years there was an inverse relationship between age group and EAP utilization rates. The average utilization rate for employees ages 16 to 29 was $10.5 \%$, whereas the average utilization rate for employees ages 59 and older was $6.5 \%$. However, because the differences were not significant across all age groups (see Table 3), Hypothesis 2 (that there would not be age differences across the years of the study) was supported.

The problems for which employees sought EAP counseling were provided by the EAP provider. The clinician for each case provided the reasons why employees sought EAP counseling under the variable, "main problem category for Year (X)." We coded these clinical data into five major categories: (1) addiction/dependency, (2) personal, (3) family/marital, (4) work related, and (5)

${ }^{2}$ Although it is possible to model cross-classification in HLM, we were unable to do so because we did not have information in the data set as to when employees transferred stores. 
Table 1

Number of EAP-Eligible Employees, Number of EAP Cases, and EAP Utilization Rates Within and Across the 3 Years of the Study

\begin{tabular}{lccc}
\hline Year & No. of employees & No. of EAP cases & \% EAP utilization \\
\hline 1 & 3,080 & 361 & 11.7 \\
2 & 3,239 & 272 & 8.4 \\
3 & 3,135 & 250 & 8.0 \\
$M$ & 3,151 & 294 & 9.4 \\
\hline
\end{tabular}

Note. $\quad \chi^{2}=30.92, p<.001 . \mathrm{EAP}=$ employee assistance program.

other. (Although some employees sought counseling for multiple reasons, only the primary reason for seeking help was considered in this research.) The addiction/dependency category consisted of employees whose primary problem was alcohol abuse/dependency, substance abuse/dependency, polysubstance abuse, gambling, and sexual addiction. The personal category consisted of employees who suffered from anger/impulsivity, anxiety disorder, bereavement, pain, mood disorder, stress, physical/verbal abuse, low self-esteem, and suicide. The family/marital category consisted of employees who suffered from extended family relations, family conflict, marital conflict, parentchild relations, and divorce. The work-related category consisted of employees whose primary problem concerned employment; for example, work burnout/stress, career/job dissatisfaction, low job motivation or performance, poor work relations, and poor work/life balance. The category "other" was used when the problem did not fit into the first four categories or when it was listed by the clinician as "other." For example, real estate issues and debt consolidation issues were coded as other.

Hypothesis 3 was also supported. Across the 3 years of the study, the majority of EAP cases consisted of either personal $(42.2 \%)$ or family/marital (40.5\%) issues, followed by work-related cases $(5.9 \%)$. However, only $4.4 \%$ were chemical dependency related. The proportion of EAP cases under each problem category varied between male and female employees over the 3 years of the study, $\chi^{2}(4, N=883)=21.26, p<.001$. Male employees were more likely to seek EAP counseling for work or addiction/dependency reasons, whereas female employees were more likely to seek EAP

Table 2

Utilization Rates by Gender Category Across 3 Years

\begin{tabular}{|c|c|c|c|c|}
\hline \multirow{2}{*}{$\begin{array}{l}\text { Year and } \\
\text { gender }\end{array}$} & \multicolumn{2}{|c|}{ EAP use } & \multirow[b]{2}{*}{$x^{2}$} & \multirow[b]{2}{*}{$\%$ EAP utilization } \\
\hline & No & Yes & & \\
\hline Year 1 & & & $30.77^{\text {**** }}$ & \\
\hline Female & 1,550 & 261 & & 14.4 \\
\hline Male & 1,269 & 100 & & 9.9 \\
\hline Total & 2,819 & 361 & & 11.4 \\
\hline Year 2 & & & $12.91^{\text {***** }}$ & \\
\hline Female & 1,707 & 187 & & 9.9 \\
\hline Male & 1,260 & 85 & & 6.3 \\
\hline Total & 2,967 & 272 & & 8.4 \\
\hline Year 3 & & & $7.09^{* *}$ & \\
\hline Female & 1,678 & 167 & & 9.1 \\
\hline Male & 1,207 & 83 & & 6.4 \\
\hline Total & 2,885 & 250 & & 8.0 \\
\hline
\end{tabular}

Note. $\quad \mathrm{EAP}=$ employee assistance program.

${ }^{* *} p<.01 .^{* * * *} p<.001$. 
Table 3

EAP Utilization Rates by Age for 3 Years of Study

\begin{tabular}{|c|c|c|c|c|}
\hline $\begin{array}{c}\text { Age } \\
\text { category }\end{array}$ & No. of employees & No. of EAP cases & $\%$ Utilization & $\chi^{2}(4)$ \\
\hline Year 1 & & & & 6.28 \\
\hline $16-29$ & 594 & 69 & 11.6 & \\
\hline $30-39$ & 1,023 & 134 & 13.1 & \\
\hline $40-49$ & 1,000 & 118 & 11.8 & \\
\hline $50-59$ & 407 & 36 & 8.8 & \\
\hline$>59$ & 56 & 4 & 7.1 & \\
\hline Year 2 & & & & 3.89 \\
\hline $16-29$ & 599 & 62 & 10.4 & \\
\hline $30-39$ & 1,051 & 84 & 8.0 & \\
\hline $40-49$ & 1,057 & 86 & 8.1 & \\
\hline $50-59$ & 458 & 35 & 7.6 & \\
\hline$>59$ & 74 & 5 & 6.8 & \\
\hline Year 3 & & & & 6.98 \\
\hline $16-29$ & 613 & 58 & 9.5 & \\
\hline $30-39$ & 1,002 & 90 & 9.0 & \\
\hline $40-49$ & 1,010 & 71 & 7.0 & \\
\hline $50-59$ & 439 & 27 & 6.2 & \\
\hline$>59$ & 71 & 4 & 5.6 & \\
\hline
\end{tabular}

Note. The $\chi^{2}(4)$ values for all 3 years were nonsignificant, with an alpha set at .05 , indicating that yearly employee assistance program (EAP) utilization rates did not significantly vary by age category.

counseling for family/marital reasons. Presenting problems by gender and year are presented in Table 4.

\section{HLM Results}

We used two-level HLM to statistically test Hypothesis 4, in which time (three yearly measures of absenteeism in hours; Level $1, n=7,742$ ) was nested within individual employees (Level 2, $n=2,584$; Snijders, 1996). Of specific interest in this study was the way in which employees' yearly absenteeism hours (which constituted the Level 1 criterion variable) related to both time (three measures across 3 years; Level 1 predictor variable) and use of the EAP (a Level 2 individual variable). In investigating this relationship, we controlled for employees' age, gender, and whether they had transferred stores anytime between Year 1 and Year 3, as these variables had different distributions between EAP users and non-EAP users. Descriptive statistics and correlations between employees' absentee rates for Years 1, 2, and 3 are shown in Table 5.

To examine the absenteeism hypothesis, our model testing proceeded in four phases. For an outline of the full Level 1, Level 2, and multilevel models, see the Appendix. The results from each model tested can be found in Table 6 . Figure 1 provides graphics comparing yearly absentee means for those who used EAP services in a given year versus those who did not use EAP services.

The first step in the application of HLM was to check the intraclass correlation (ICC) of the dependent variable with the unconditional model (Model A in Table 6), called the null model, in which all independent variables were excluded from the equation. The unconditional model is conducted to justify the use of a two-level model; that is, to determine whether there were both intraand interindividual differences in absenteeism hours (see Raudenbush \& Bryk, 2002). As expected, there were differences at both levels with an ICC of .42. The ICC indicated that $42 \%$ of the variance in yearly absenteeism hours was due to differences among employees and $58 \%$ of the variance in yearly absenteeism was due to individuals' yearly absenteeism rates changing year to year. Because variance existed at both levels of the data structure, predictors were added separately at each level of analysis. 
Table 4

Number and Percentage of Employee Assistance Program (EAP) Cases by Reason for Seeking Help and Gender for 3 Years

\begin{tabular}{|c|c|c|c|c|c|}
\hline \multirow{2}{*}{$\begin{array}{l}\text { Reason for } \\
\text { seeking EAP } \\
\text { services }\end{array}$} & \multicolumn{2}{|c|}{ Female EAP cases } & \multicolumn{2}{|c|}{ Male EAP cases } & \multirow[b]{2}{*}{$\chi^{2}(4)$} \\
\hline & No. & $\%$ & No. & $\%$ & \\
\hline \multicolumn{6}{|c|}{ Year 1} \\
\hline Dependency & 9 & 3.4 & 6 & 6.0 & \\
\hline Personal & 111 & 42.5 & 44 & 44.0 & \\
\hline Family/marital & 119 & 45.6 & 40 & 40.0 & \\
\hline Work related & 11 & 4.2 & 5 & 5.0 & \\
\hline Other & 11 & 4.2 & 5 & 5.0 & \\
\hline Total cases & 261 & & 100 & & 1.89 \\
\hline \multicolumn{6}{|c|}{ Year 2} \\
\hline Dependency & 6 & 3.2 & 8 & 9.4 & \\
\hline Personal & 83 & 44.4 & 38 & 44.7 & \\
\hline Family/marital & 75 & 40.1 & 27 & 31.8 & \\
\hline Work related & 5 & 2.7 & 8 & 9.4 & \\
\hline Other & 18 & 9.6 & 4 & 4.7 & \\
\hline Total cases & 187 & & 85 & & $12.75^{*}$ \\
\hline \multicolumn{6}{|c|}{ Year 3} \\
\hline Dependency & 3 & 1.8 & 7 & 8.4 & \\
\hline Personal & 68 & 40.7 & 30 & 36.1 & \\
\hline Family/marital & 69 & 41.3 & 31 & 37.3 & \\
\hline Work related & 10 & 6.0 & 11 & 13.3 & \\
\hline Other & 17 & 10.2 & 4 & 4.8 & \\
\hline Total cases & 167 & & 83 & & $12.00^{*}$ \\
\hline \multicolumn{6}{|c|}{ Total for 3 years } \\
\hline Dependency & 18 & 2.9 & 21 & 7.8 & \\
\hline Personal & 262 & 42.6 & 112 & 41.8 & \\
\hline Family/marital & 263 & 42.8 & 98 & 36.6 & \\
\hline Work related & 26 & 4.2 & 24 & 9.0 & \\
\hline Other & 46 & 7.5 & 13 & 4.9 & \\
\hline Total cases & 615 & & 268 & & $21.26^{* * * *}$ \\
\hline
\end{tabular}

Note. $\quad \chi^{2}(4)$ represents comparisons between male and female EAP users' distributions of reasons for seeking EAP services.

${ }^{*} p<.05 . \quad{ }^{* * * *} p<.001$.

Next, how yearly absenteeism changed across the 3 years, regardless of group membership was examined. Although this was not a main focus of our research, any drastic changes across the years of the study would likely indicate the effects of confounding variables on absenteeism. It is also important to determine the trajectory of change in absenteeism across years (i.e., linear vs. quadratic change). To examine both linear and quadratic change, we used a random regression coefficient model (Model B in Table 6; Raudenbush \& Bryk, 2002). In this model, only Level 1 predictors are included (in this case, the linear and quadratic changes in absenteeism across years). The following coding system was used to examine the linear change (Year $1=1$; Year $2=2$; Year $3=3$ ) and quadratic change (year centered and then squared, thus dummy coded: Year 1 = 1; Year $2=0$; Year $3=1$ ) of absenteeism across years. Centering the year variable made Year 2 the intercept, and by squaring the year variable, we were able to examine whether absenteeism rates increased or decreased from Year 1 to Year 2 and then returned to a similar level to Year 1 again in Year 3. This 
Table 5

Summary of Means, Standard Deviations, and Intercorrelations for Yearly Hours of Absenteeism

\begin{tabular}{lccccc}
\hline Year & $M$ & $S D$ & 1 & 2 & 3 \\
\hline 1. Year 1 & 30.42 & 38.24 & - & & \\
2. Year 2 & 33.74 & 41.15 & $.44^{* * * *}$ & - & \\
3. Year 3 & 34.55 & 42.19 & $.40^{* * *}$ & $.43^{* * * *}$ & - \\
\hline
\end{tabular}

Note. Pearson correlations represent the relationship between individuals' $(N=2,584)$ absenteeism rates across the 3 years.

$* p<.001$.

method was driven by the expectation that those who utilized the EAP in Year 2 might have experienced increased rates of absenteeism in Year 2 compared with other years.

The results of this model indicated that, at the intercept (Year 1), the average annual absenteeism was $29.61 \mathrm{hr}$ and the average absenteeism rate increased by an average of $2.39 \mathrm{hr}$ each subsequent year, $\left(\beta_{10}=2.39, p<.001\right)$. These figures represent the intercept and slope for all employees (i.e., no Level 2 predictors such as EAP use). The reason for the average absenteeism increasing from one year to the next is unknown. The quadratic coefficient for time was negative but not statistically significant. Thus, a linear relationship of absenteeism across time was a better fit to the data than the quadratic term when examining all employees (e.g., on average, absenteeism increased at a steady rate from one year to the next).

Next, we examined group differences across all years (the data were aggregated across all 3 years) using a means-as-outcomes model (Model C in Table 6). In this model, Level 2 predictors are added but no Level 1 predictors (i.e., time was ignored). This allowed us to examine whether groups differed in absenteeism across all 3 years of the study. The Level 2 predictors included age (grand-centered to make the intercept meaningful), ${ }^{3}$ gender (female $=0$, male $=1$ ), job transfer $($ no $=0$, yes $=1)$, and an EAP usage variable $($ no $=0$, yes $=1)$ for each year.

The results of the model revealed statistical significance for age and job transfer only $\left(\beta_{02}=0.38, p<.001 ; \beta_{03}=-4.44, p<.001\right.$, respectively). These findings demonstrated that older (those above the sample mean) employees tended to have higher rates of absenteeism compared with younger employees (those below the mean). Also, those who transferred stores (possibly as a result of promotion) during the course of the study had, on average, 4.4 fewer yearly absentee hours than did those who had not transferred. On average, across all 3 years of the study, male employees had higher amounts of absenteeism than female employees, but the difference was not statistically significant.

Across the 3 years of the study, those who used the EAP in Year 1 did not have significantly different amounts of absenteeism than non-Year 1 EAP users. The same nonsignificant relationship was found among EAP usage in Year 2 and Year 3, demonstrating no statistically significant mean differences in absenteeism across all 3 years between those who used EAP in any given year and those who did not.

Finally, we tested the intercepts- and slopes-as-outcomes model (Raudenbush \& Bryk, 2002) to gain a better understanding of the relationship between EAP usage and annual employee absenteeism. The intercepts- and slopes-as-outcomes model allows individuals' intercepts and slopes of absenteeism to vary on the basis of individual characteristics (e.g., EAP use, gender, age). The model (Model D in Table 6) included EAP use variables (EAP use in Year 1, Year 2, and Year 3) and age (centered), gender, and moved stores as covariates. Because the quadratic term was not

\footnotetext{
${ }^{3}$ A discussion of centering is beyond the scope of this article. However, the interested reader should see Enders and Tofighi (2007) for a thorough discussion regarding the complex issues surrounding centering in hierarchical linear modeling.
} 


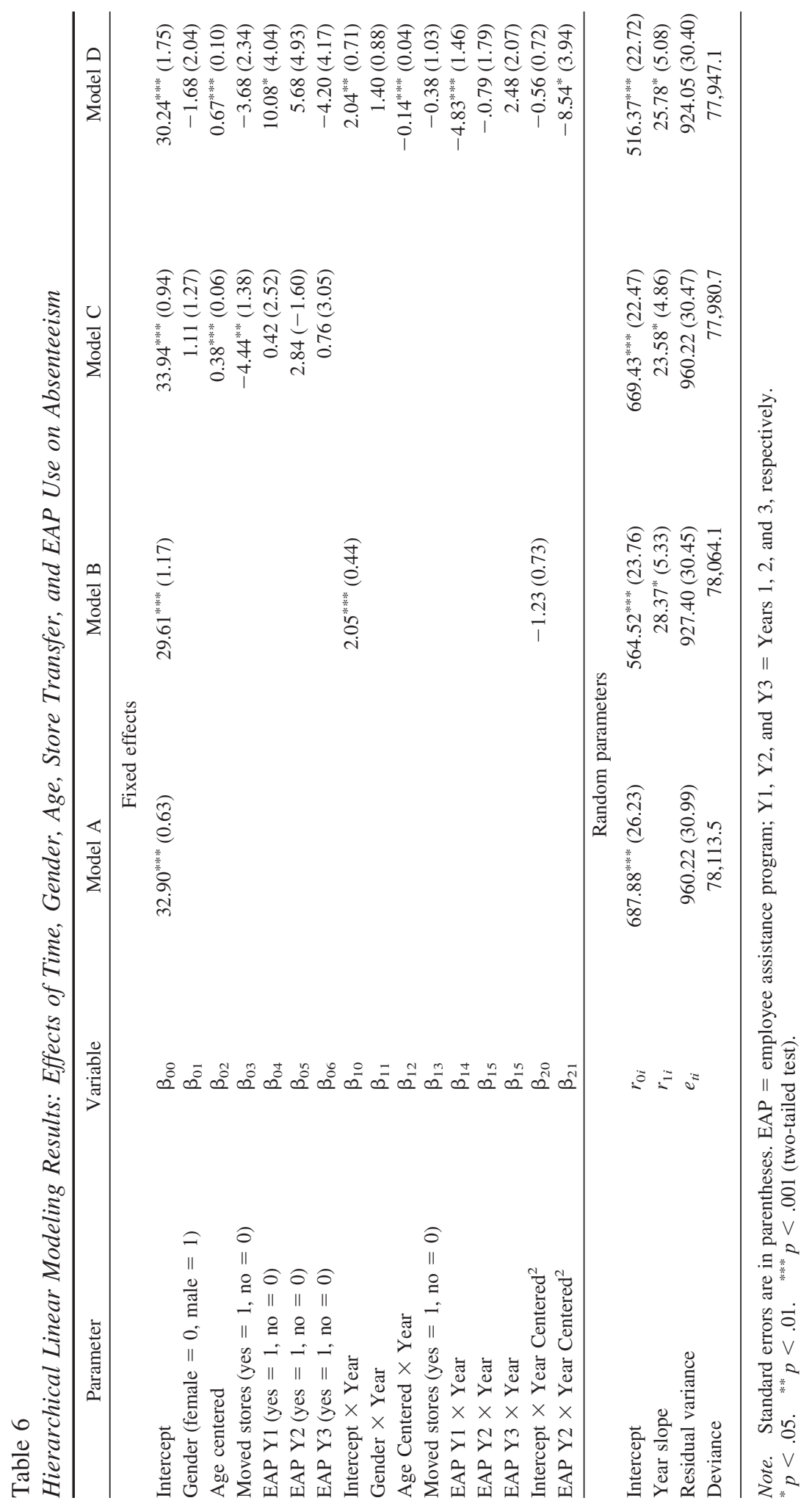



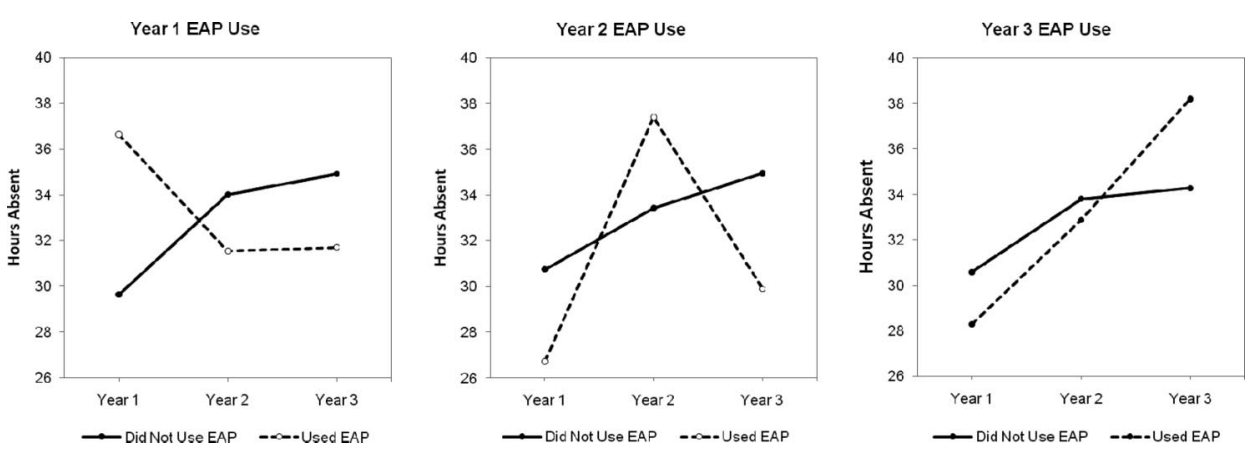

Figure 1. Comparison of mean absenteeism rates for those who used employee assistance program (EAP) services versus those who did not use EAP services.

significant in the random regression coefficient model, the quadratic term was only used for one cross-level interaction (Year Centered and Squared $\times$ Y2 EAP Use) in the final model to Test Hypothesis 4. Again, it was anticipated that those who used EAP services in Year 2 of the study would increase in absenteeism from Year 1 to Year 2 and then decrease in absenteeism from Year 2 to Year 3; again, that was what was found, supporting Hypothesis 4.

The results of the model testing also found that the intercept of age in terms of yearly absenteeism was positive and statistically significant $\left(\beta_{02}=0.67, p<.001\right)$, indicating that the intercept of absenteeism increased $0.67 \mathrm{hr}$ for every year over the mean age of employees. The interaction of age and year (slope) was also statistically significant but conversely negative $\left(\beta_{12}=\right.$ $-0.141, p=.001$ ), indicating that, on average, as employees' age increased absenteeism rates went up in Year 1 but the strength of this relationship decreased from Year 1 to Year 3. Both the intercept and slope of gender were nonsignificant in the intercepts- and slopes-as-outcomes model $(p>.05)$, indicating no clear relationship between gender and absenteeism. Both the intercept and slope of whether employees transferred stores were also not significant in the intercepts- and slopes-asoutcomes model ( $p>.05)$, suggesting no clear relationship between job transfer and absenteeism.

The EAP variables in the intercept- and slopes-as-outcomes model were of most interest to our study. Consistent with Hypothesis 4 , the intercept of Year 1 EAP use was significant $\left(\beta_{04}=10.08\right.$, $p<.05$ ). Thus, those who used EAP in Year 1 had significantly higher rates of absenteeism in the year of using the EAP than did those who did not use EAP in that year. The interaction of time (linear) and Year 1 EAP use was also significant, but the relationship was negative $\left(\beta_{14}=-4.83\right.$, $p<.001)$. This indicates that, in Year 1, EAP users had, on average, higher rates of absenteeism than did non-EAP users, but in Year 2 there were no differences between the groups in absenteeism and in Year 3, Year 1 EAP users had lower absenteeism rates than did non-Year 1 EAP users on average, offering partial support for Hypothesis 4.

Next, we examined the relationship of absenteeism for Year 2 EAP usage and absenteeism over Years 1 to 3. For these analyses, however, we had both a baseline year (before EAP usage) and data from the year of EAP usage and the year after EAP usage compared with the controls (non-EAP usage). Again, consistent with Hypothesis 4, the intercept of Year 2 EAP use was not significant $(p>.05)$. Thus, Year 2 EAP users and nonusers did not differ in absenteeism rates in the baseline year, here termed Year 1. Supporting Hypothesis 4, the cross-level interaction of year linear and Year 2 EAP use was also not significant. From Year 1 to Year 3, the linear change in yearly absenteeism did not differ between those who utilized EAP in Year 2 and those who did not. However, the coefficient for quadratic change in absenteeism for Year 2 EAP use was significant $\left(\beta_{21}=-8.54, p<.05\right)$. This finding indicated that, compared with non-Year 2 EAP users, on average, EAP users increased in absenteeism from Year 1 to Year 2 and then decreased from Year 2 to Year 3. Consistent with Hypothesis 4, this suggests that EAP usage primarily affects absenteeism in the year of using the EAP (presumably the year the problem was experienced), not in the year before or the year after treatment. 
To further test the contention in Hypothesis 4 that absenteeism rates of EAP users and nonusers in the years before the year of EAP use would be lower than in the year of use, we predicted that Year 3 EAP users would have nonsignificant intercept differences in absenteeism compared with non-Year 3 EAP users (i.e., Year 1 absenteeism was expected to be the same for both groups). However, if Year 3 EAP users, as hypothesized, had higher rates of absenteeism in Year 3 of the study, the slope for absenteeism would be expected to be greater for Year 3 EAP users compared with nonusers. The intercept of Year 3 EAP use was not significant $(p>.05)$. Thus, Year 3 EAP users and non-Year 3 users did not differ in absenteeism rates in Year 1. Contrary to Hypothesis 4, however, the interaction of year linear and Year 3 EAP use was also not significant. Although Year 3 EAP users did have a slightly steeper slope in absenteeism than did non-Year 3 EAP users $\left(\beta_{15}=2.48\right)$, this difference was not significant, $p>.05$.

\section{Discussion}

Our study provided, to our knowledge, some of the best longitudinal data yet published on EAP usage across an entire national (Canadian) corporation using a standard definition of EAP utilization rate. Our hypotheses about demographic analyses supported the idea that women used EAP services more than did men. Although there were some differences in age (the oldest employees in the sample used EAP services less than did the youngest), as hypothesized, there were no statistically significant age differences in EAP utilization across all of the age groups. Finally, we found two major reasons for using the EAP: personal problems and marital/family problems.

This study also demonstrated that absenteeism, when measured across a multiple-year period, was related to utilization of EAP services but that this relationship was complex. Consistent with Macdonald et al.'s studies (Macdonald et al., 1997; Macdonald et al., 2000), employees had higher rates of absenteeism in the year of EAP usage. However in contrast to other research, employees' rate of absenteeism subsequently went down in the year(s) after EAP usage (and was no different in the year before EAP usage). One possible explanation for this phenomenon may be that employees may be missing work in the year of EAP usage to attend EAP sessions or to manage their presenting problems in other ways that involve time away from work but that once the problems are presumably addressed, absenteeism returns to its baseline. Because psychological problems have been shown to be related to physical illness (DeLongis, Folkman, \& Lazarus, 1988) it is also possible that employees using the EAP may be more prone to physical illness during the times when they are accessing the EAP and absenteeism may result from the co-occurrence of physical illness and emotional distress.

This study incorporated the unusual and, to our knowledge, unprecedented feature of being able to track absenteeism with respect to EAP usage across multiple years. We found that, for employees who utilized EAP services in Year 1, their absenteeism rates were higher in that year but decreased in subsequent years. We found a similar trend for those utilizing the EAP in Year 2. Their absenteeism rate was higher in Year 2 but was not any higher than non-EAP users in either the year before or the year after their EAP use. Finally, for those using the EAP in Year 3, although they did miss more work that year than did those not using the EAP, this difference was not statistically significant. Together, these results demonstrate that, across time, employees who use an EAP appear not to miss significantly more days than employees who did not use EAP except in the year of EAP use. This implies that researchers should not examine absenteeism as an outcome measure only in short-term contexts and that employees using EAP services are not likely to have attendance problems over time. (For those using the EAP in Year 1, their lowered absenteeism from the year of using the EAP continued for 2 years beyond the initial year of EAP utilization.) Put another way, these findings suggest that consulting psychologists and managers need to understand the idea of short-term "pain" for long-term "gain" when it comes to help seeking for personal and family problems in organizational contexts.

What might account for the pattern of absenteeism findings? One possibility is that the short-term model of EAP, which focuses on mobilizing employees' own resources, serves to buffer employees from some of the negative outcomes of potential future problems. Another potential explanation why EAP users may experience lower rates of absenteeism in the years after EAP use could be that employees who could benefit the most from the EAP are not using it. By not addressing their problems, these employees 
may end up with higher rates of absenteeism than those who do address their problems. This notion is supported by a survey by Reynolds and Lehman (2003), who found that employees who might benefit most from EAP services are often the most reluctant to use the services.

\section{Limitations and Directions for Future Research}

A limitation of most research in the field of EAP usage and absenteeism concerns the ability to randomly assign persons to conditions. Ideally, research evaluating the impact of EAP on absenteeism would randomly assign a group of employees matched on problems to treatment (EAP) or control conditions. Although this would be a more methodologically sound approach, the process of random assignment would raise ethical concerns for most companies using EAP services and would violate the purpose of most EAPs today, which aim to provide confidential and immediate support for those employees in need. Given this restriction, our approach of comparing employees who utilized EAP services to those who did not is one valuable alternative methodology. The findings from this design are tempered, however, by the lack of a comparison group of employees in the same type of organization who did not have access to EAP services.

Another issue to be considered in interpreting our results is that EAP users and non-EAP users are presumably self-selected groups and could be speculated to differ from each other on EAPoutcome-relevant characteristics. Future research might use a similar design as ours but also compare use of the EAP by a group of employees matched on presenting problem, perhaps determined by an organizationwide survey. Additionally, future research would benefit from comparing long-term trends in organizations that have EAP benefits compared with similar organizations without access to EAP and also by replicating our study across different industries.

Another limitation to our study — but also a strength — was the use of a single organization. Although this may limit the generalizability of the findings to similar types of organizations, the inclusion of all employees in a national sample from the same organization but across all organizational units was, to our knowledge, unprecedented in the literature.

Finally, there were several other limitations of this study that may be addressed by future research. First, the present study also did not have any mechanism for examining the phenomenon of presenteeism - the tendency for employees to be physically present in the workplace but not engaged (in this context, presumably because of their personal problems or issues). Also, although our study was able to demonstrate some attributes of employee absenteeism, we did not examine the impact that absenteeism had on productivity in the workplace. Additionally, absenteeism may not be a significant negative organizational outcome in all organizations.

\section{Practical Implications}

Consulting psychologists and managers should find the results of this study important for practical decision making. A sufficiently large group of employees in any one year needs and makes use of an EAP when it is provided. Such usage does not come at the expense of increased employee absenteeism. On the basis of previous positive research findings (see Attridge et al., 2009, for a review) about satisfaction and clinical outcomes associated with EAP usage, coupled with our new finding, it appears that organizations would benefit from efforts to install EAPs when they are absent and to encourage increased EAP utilization by those in need. The advantageous findings demonstrated in the present study, coupled with the destigmatizing of help seeking for personal, family, or work-related problems, is likely to encourage employers to work toward ensuring that all employees are aware of these benefits without worrying about the possible cost of absenteeism associated with increased utilization. Most important, the present study provides a methodologically sound substantiation of the benefits of EAP on one organizationally important outcome measure over a longer period of time than has previously been explored.

The study also suggests that consulting psychologists with clinical and counseling training can find a useful outlet for that background and skill set in EAP work in organizations. Because personal stress and problems affect a significant minority of employees, the news from this study is that employers are well advised to seek out consultants who can help them address such employee needs and problems. 


\section{References}

Alander, R., \& Campbell, T. (1975). An evaluative study of an alcohol and drug recovery program: A case study of the Oldsmobile experience. Human Resources Management, 14, 14-18.

Arthur, A. R. (2000). Employee assistance programmes: The emperor's new clothes of stress management? British Journal of Guidance \& Counselling, 28, 549-559.

Asma, F. E., Hilker, R. J., Shevlin, J. J., \& Golden, R. G. (1980). Twenty-five years of rehabilitation of employees with drinking problems. Journal of Occupational Medicine, 22, 241-244.

Attridge, M., Herlihy, P., Sharar, D., Amaral, T., McPherson, T., Stephenson, D., . . \& Routledge, S. (2009). Utilization of EAP services [White paper]. Arlington, VA: Employee Assistance Society of North America: Retrieved from http:// www.easna.org/wp-content/uploads/2010/08/EASNAResearchNotesNo5UtilizationDEC2009102209.pdf

Azzone, V., McCann, B., Merrick, E. L., Hiatt, D., Hodgkin, D., \& Horgan, C. (2009). Workplace stress, organizational factors and EAP utilization. Journal of Workplace Behavioral Health, 24, 344-356.

Barlow, D. H. (Ed.). (2008). Clinical handbook of psychological disorders: A step-by-step treatment manual (4th ed.). New York: Guilford Press.

Blum, T. C., Martin, J. K., \& Roman, P. M. (1992). A research note on EAP prevalence, components and utilization. Journal of Employee Assistance Research, 1, 209-229.

Blum, T. C., \& Roman, P. M. (1992). A description of clients using employee assistance programs. Alcohol Health and Research World, 16, 102-128. Retrieved from http://www.ebscohost.com/ehost/detail?vid= $8 \& b k=1 \&$ hid $=11 \& \operatorname{sid}=03 \mathrm{cc} 6 \mathrm{~b} 26-26 \mathrm{~d} 6-435 \mathrm{~d}-\mathrm{aaaa}-5 \mathrm{ad} 693230 \mathrm{cc} 4 \% 40$ sessionmgr $10 \& \mathrm{bdata}=$ JnNpdGU9ZWhvc3QtbG12ZSZzY29wZT1zaXRl\#db=ulh\&AN=9303010506

Cahill, M., Volicer, B., \& Newberger, E. (1982). Female referral to employee assistance programs: The impact of specialized intervention. Drug \& Alcohol Dependency, 10, 223-233.

Carr, J. C., \& Hellan, T. H. (1980). Improving corporate performance through employee-assistance programs. Business Horizons, 23, 57-61.

Cohen, S., \& Williamson, G. M. (1991). Stress and infectious disease in humans. Psychological Bulletin, $109,5$.

Cooper, C. L., Dewe, P., \& O’Driscoll, M. (2003). Employee assistance programs. In J. Quick \& L. Tetrick (Eds.), Handbook of occupational health psychology (pp. 289-305). Washington, DC: American Psychological Association.

Courtois, P., Hajek, M., Kennish, R., Paul, R., Stockert, T., \& Thompson, T. (2004). Performance measures in the employee assistance program. Employee Assistance Quarterly, 19, 45-58.

Csiernik, R. (2002). An overview of employee and family assistance programming in Canada. Employee Assistance Quarterly, 18, 17-33.

Csiernik, R. (2003). Employee assistance program utilization: Developing a comprehensive scorecard. Employee Assistance Quarterly, 18, 45-60.

DeLongis, A., Folkman, S., \& Lazarus, R. S. (1988). The impact of daily stress on health and mood: Psychological and social resources as mediators. Journal of Personality and Social Psychology, 54, 486-495.

Employee Assistance Professionals Association. (2009). EAP utilization [White paper]. Arlington, VA: Author. Retrieved from http://www.eapassn.org/files/public/utilization09.pdf

Enders, C. K., \& Tofighi, D. ( 2007). Centering predictor variables in cross-sectional multilevel models: A new look at an old issue. Psychological Methods, 12, 121-138.

Every, D., \& Leong, D. (1995). Exploring EAP cost-effectiveness: Profile of a nuclear power plant internal EAP. Employee Assistance Quarterly, 10, 1-12.

Farrell, D., \& Stamm, C. L. (1988). Meta-analysis of the correlates of employee absenteeism. Human Relations, 41, 211-227.

Foote, A. J., Erfurt, J. C., Strauch, P. A., \& Guzzardo, T. L. (1978). Cost effectiveness of occupational employee assistance programs: Test of an evaluation method. Ann Arbor: The University of Michigan Institute of Labor and Industrial Relations.

Freedberg, E. J., \& Johnston, W. E. (1979). Changes in drinking behavior, employment status and other life areas for employed alcoholics three, six and twelve months after treatment. Journal of Drug Issues, 9, 523-534.

French, M. T., Dunlap, L. J., Roman, P. M., \& Steele, P. D. (1997). Factors that influence the use and perceptions of employee assistance programs at six worksites. Journal of Occupational Health Psychology, 2, 312-324.

Gerstein, L., Moore, D. T., Duffey, K., \& Dainas, C. (1993). The effects of biological sex and ethnicity on EAP utilization and referrals. Consulting Psychology Journal, 45, 1061-4087.

Greenwood, K. L., DeWeese, P., \& Inscoe, P. S. (2005). Demonstrating the value of EAP services: A focus on clinical outcomes. Journal of Workplace Behavioral Health, 21, 1-10. 
Groeneveld, J., \& Shain, M. (1985). The effect of corrective interviews with alcohol dependent employees: A study of 37 supervisor-subordinate dyads. Employee Assistance Quarterly, 1, 63-74.

Hackett, R. D., \& Bycio, P. (1996). An evaluation of employee absenteeism as a coping mechanism among hospital nurses. Journal of Occupational and Organizational Psychology, 69, 327-338.

Hargrave, G. E., Hiatt, D., Alexander, R., \& Shaffer, I. A. (2008). EAP treatment impact on presenteeism and absenteeism: Implications for return on investment. Journal of Workplace Behavioral Health, 23, 283-293.

Hargrave, G. E., Hiatt, D., \& Shaffer, I. A. (2007). The impact of mental health disorders on work productivity. EAP Digest, 27, 34-35.

Harris, M. M., \& Fennell, M. L. (1988). Perceptions of an employee assistance program and employees' willingness to participate. Journal of Applied Behavioral Science, 24, 423-438.

Hays, R. D., Wells, K. B., Sherbourne, C. D., Rogers, W., \& Spitzer, K. (1995). Functioning and well-being outcomes of patients with depression compared with chronic general medical illnesses. Archives of General Psychiatry, 52, 11-19.

Hummer, J., Sherman, B., \& Quinn, N. (2002). Present and unaccounted for. Occupational Health \& Safety, 71, 40-44. Retrieved from http://www.ncbi.nlm.nih.gov/pubmed/11977562

Jacobson, J. M., \& Jones, A. L. (2010). Standards for the EAP profession: Isn't it time we all start speaking the same language? Journal of Behavioral Health, 25, 1-18.

Johns, G. (1997). Contemporary research on absence from work correlates, causes and consequences. In C. L. Cooper \& I. T. Robertson. International review of industrial and organizational psychology (Vol. 12, pp. 115-174). New York: Wiley.

Johns, G. (2001). The psychology of lateness, absenteeism, and turnover. In N. Anderson, D. S. Ones, H. K. Sinangil, \& C. Viswesvaran (Eds.), Handbook of industrial organizational psychology: Vol. 2. Organizational psychology (pp. 232-252). London: Sage.

Johns, G. (2010). Presenteeism in the workplace: A review and research agenda. Journal of Organizational Behavior, 31, 519-542.

Johns, G., \& Xie, J. L. (1998). Perception of absence from work: People's Republic of China versus Canada. Journal of Applied Psychology, 83, 515-530.

Johnson, J. D. (2008). Employee assistance programs: Sources of assistance relations to inputs and outcomes. Journal of Workplace Behavioral Health, 23, 263-282.

Lennox, R., Sharar, D., \& Burke, J. (2009). Measuring workplace outcomes in EAPs. Journal of Employee Assistance, 39, 18-19. Retrieved from http://www.eapassn.org/files/public/outcomes0110.pdf

Lowman, R. L. (1993). Counseling and psychotherapy of work dysfunctions. Washington, DC: American Psychological Association.

Lowman, R. L. (Ed.). (2002). Handbook of organizational consulting psychology. San Francisco: Jossey-Bass.

Macdonald, S., Lothian, S., \& Wells, S. (1997). Evaluation of an employee assistance program at a transportation company. Evaluation and Program Planning, 20, 405-505. Retrieved from http://www.elsevier.com/wps/ find/journaldescription.cws_home/593/description\#description

Macdonald, S., Wells, S., Lothian, S., \& Shain, M. (2000). Absenteeism and other workplace indicators of employee assistance program clients and matched controls. Employee Assistance Quarterly, 15, 41-57.

Mazloff, D. C. (1996). Understanding employee assistance programs: A case study of communication strategies and utilization patterns. Dissertation Abstracts International: Humanities and Social Sciences, 56(11A), 4204.

Merrick, E. L., Volpe-Vartanian, J., Horgan, C. M., \& McCann, B. A. (2007). Revisiting EAPs and workplace substance abuse: Key issues and a research agenda. Psychiatric Services, 58, 1262-1264.

Milne, S., Blum, T. C., \& Roman, P. M. (1994). Predicting the decision to utilize an employee assistance program: A LISREL analysis. Personnel Psychology, 47, 224-245.

Mulligan, P. M. (2007). The prevalence of employee assistance programs and the employee participation rates of Long Island companies. Proceedings of the Northeast Business \& Economics Association, 68-71.

Murphy, L. R. (2000). Employee assistance programs. In A. E. Kazdin (Ed.), Encyclopedia of psychology: Vol. 3 (pp. 182-183). Washington, DC: American Psychological Association.

Panks, J. G. (2001). The utilization of employee assistance program services by managers. Unpublished doctoral dissertation, Wayne State University.

Petersen, J. E. (1972). INSIGHT: A management program of help for troubled people. Labor Law Journal, 23, 492-495.

Pompe, J. C., \& Sharar, D. A. (2008). Preparing for the challenges of the Employee Assistance Research Foundation: A response to Carl Tisone's call to action. Journal of Workplace Behavioral Health, 23, 217-227. 
Poverny, L. M., \& Dodd, S. J. (2000). Differential patterns of EAP service utilization: A nine-year follow-up study of faculty and staff. Employee Assistance Quarterly, 15, 29-42.

Raudenbush, S. W., \& Bryk, A. S. (2002). Hierarchical linear models: Applications and data analysis methods (2nd ed.). Thousand Oaks, CA: Sage.

Reynolds, G. S., \& Lehman, W. E. (2003). Levels of substance use and willingness to use the employee assistance program. Journal of Behavioral Health Services and Research, 30, 238-248.

Selvik, R., Stephenson, D., Plaza, C., \& Sugden, B. (2004). EAP impact on work, relationship, and health outcomes. Journal of Employee Assistance, 34, 18-22.

Shumway, S. T., Wampler, R. S., \& Arredondo, R. (2004). A need for marriage and family services: A survey of employee assistance program client problems and needs. Employee Assistance Quarterly, 19, 61-71.

Snijders, T. (1996). Analysis of longitudinal data using the hierarchical linear model. Quality \& Quantity, 30, 405-426.

Tisone, C. R. (2008). Employee assistance research foundation: A call to action. Journal of Workplace Behavioral Health, 23, 205-215.

Ulleberg, P., \& Rundmo, T. (1997). Job stress, social support, job satisfaction and absenteeism among offshore oil personnel. Work \& Stress, 11, 215-228.

Weiss, R. M. (2003). Effects of program characteristics on EAP utilization. Employee Assistance Quarterly, 18, 61-70.

Whitehouse, D. (2005). Workplace presenteeism: How behavioral professionals can make a difference. Behavioral Healthcare Tomorrow, 14, 32-36.

Young, D., Reichman, W., \& Levy, M. (1987). Differential referral of women and men to employee assistance programs: The role of supervisory attitudes. Journal of Studies on Alcohol, 48, 22-28.

\section{Appendix}

\section{Yearly Absentee Hours: Multilevel Regression Model}

\section{Level 1 Model}

$Y=\pi_{0}+\pi_{1 J}$ Year $+\pi_{2 J}$ Year centered ${ }^{2}+e_{I J}$

\section{Level 2 Model}

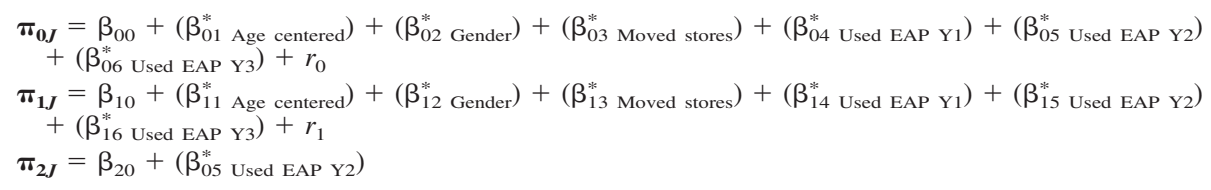

\section{Full Model}

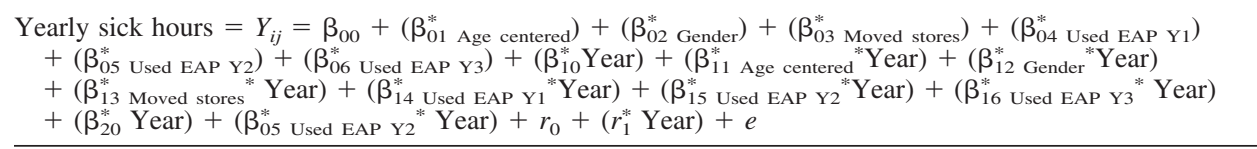

Note. $\mathrm{EAP}=$ employee assistance program; Y1, Y2, and Y3 = Years 1, 2, and 3, respectively.

Received March 23, 2011

Revision received June 9, 2011

Accepted June 10, 2011 